\title{
Improving the Wellbeing of At-Risk Youth through Media Participation
}

\author{
Mari Pienimäki
}

As a persistent societal problem in Finland, youth marginalisation invites innovative, practicebased studies. The pedagogical action research, titled Young People in the Limelight: Towards Agency through Multiliteracies, investigates the potential of including media participation as a part of media education in the context of the non-formal education of youth work to support youth, who are at risk of marginalisation, to become active agents in their lives and to build their multiliteracies. Around 100 participants, mainly aged 15-22 years, had difficult life situations or learning or social difficulties. The article examines media participation from the perspective of a theory of wellbeing called self-determination theory (SDT). The data, which mainly include observation diaries and interviews, are analysed based on three needs of wellbeing: competence, autonomy and relatedness. The results confirm the validity of SDT by showing that the participants have all three needs. They also reveal that at-risk youth find it difficult to fulfil these needs. Media participation can help them fulfil these needs, for example, by offering them expert positions and informal situations to express their autonomy and relate to others in, with and through media. Furthermore, the satisfaction of these needs improves the media participation of at-risk youth.

Keywords: youth media participation, at-risk youth, wellbeing, action research, selfdetermination theory.

\section{Introduction}

Recent studies suggest that media participation can enhance young people’s self-efficacy, autonomy, growth as social actors and sense of belonging to society (e.g., Bloustien 2007; Broderick 2014; Dekelver, Van den Bosch, and Engelen 2011; Hopkins 2010). This article focuses on the potential of including media participation in youth work as a part of media education to 
encourage youth, who are at risk of marginalisation, to engage with others, build communicative media skills and multiliteracies and take part in society. Although youth marginalisation is more widespread in countries other than a Nordic Welfare state such as Finland, it is nevertheless recognised as a problem for Finnish society, as it is persistent and possibly worsening. In 2010, Finland had 50,000 marginalised youth (5\% of all 15-29 year olds), meaning they have been unemployed for over three years and have drifted away from typical life paths (Myrskylä 2012). Based on the statistics of Me Foundation, in 2017, close to 70,000 youth were marginalised and many more are on the brink of marginalisation. The three-year media education study called Young People in the Limelight: Towards Agency through Multiliteracies (hereafter YPAM) attempts to address this problem. This action research aims to develop media education that encourages at-risk youth to participate in, with and through media, as well as to empower them and improve their multiliteracies, especially media literacy.

First, the text at hand reflects on theoretical views of media participation from diverse viewpoints and introduces the self-determination theory (hereafter SDT) dealing with wellbeing. It describes the YPAM case study and its methods, context and empirical data. The article aims to examine whether at-risk youth have the three needs of wellbeing (i.e., competence, autonomy and relatedness) introduced by SDT and how media participation within youth work can provide satisfaction for these needs. The goal is to provoke discussion on the positive value of media participation in the context of youth work particularly for at-risk youth. The final section summarises the results and reflects on the usability of SDT in media education studies.

\section{Theoretical Framework}

The concept of 'media participation' is used diversely, being linked with such issues as interaction, engagement, inclusion, democracy and power (e.g., Percy-Smith and Thomas 2010). According to Carpentier (2011), the concept is ambiguous and overstretched. Considering the broad societal 
fields penetrated by media, such as democracy, communication and the arts, he distinguishes between participation in and through media. Participation in media relates, for instance, to the production of media content and engagement with the decision-making of media organisations, while participation through media refers to 'opportunities for mediated participation in public debate and for self-representation in the variety of public spaces’. (Carpentier 2011, 67-68.) Carpentier (2011) considers media participation principally in terms of citizens’ opportunities to engage with professional media organisations and emphasises the decision-making aspect of participation, thus characterising media participation as political in a broad sense. The aspect of decision-making is also stressed in discourses on children and youth’s participation, owing mainly to the United Nations Convention on the Rights of the Child (1989) and Roger Hart's (1992) oftcited 'ladder of participation'. In Western societies, theorists endorsing politically oriented views of media participation commonly promote the idea of active citizenship (e.g., youth parliament) or criticise policy discourses that make false promises of engaging citizens (including youth) in public decision-making (e.g., Black, Walsch, and Taylor 2011; Checkoway 2011; Head 2011).

The promotion of political media participation can be valuable, especially in enhancing democracy. However, Dahlgren (2000) argues for cultural citizenship, meaning that people also need to have the ability to express their opinions and create media content in order to participate in the public sphere. Jenkins et al. (2009) claim as well that today’s participatory culture requires one to develop cultural competence and social skills for full involvement in society. Thumin (2010), in turn, explores whether the self-representation promoted by museums and diverse cultural institutions, which aim to empower 'ordinary people', is democracy, therapy or both. Head (2011), among others, highlights the significance of everyday informal participation of youth in community life and in the construction of shared experiences (e.g., Bloustien 2007; Percy-Smith 2010). In other words, besides participation in and through media, there is value in participation with media, meaning in face-to-face social activities around or with media that can engender, for example, 
shared experiences, connection to others and sense of community. In fact, according to SDT, these social outputs contribute to a person's psychological wellbeing (e.g., Deci and Ryan 2000; Ryan, Huta, and Deci 2008).

In scientific studies, socio-cultural views on media participation among youth are discussed using various concepts, such as participatory media, youth media, youth media production, community-based media production and creative media engagement (e.g., Charmaraman 2013; Hopkins 2010; Rodríguez-Jiménes and Gifford 2010). However, the issue of wellbeing is rarely addressed in these discussions (except e.g., Kotilainen and Pathak-Shelat 2015). As the YPAM study focuses on at-risk youth, it sheds light on the aspect of wellbeing arising from participation in, with and through media. Due to the aspect of wellbeing, it would be of value to include media participation in formal and non-formal media education (e.g. in schools and youth work), instead of teaching media literacy for youth merely through the critical analysis of, for instance, media texts and the practices of media organisations. In other words, becoming media literate through one's own media making and media participation can create wellbeing besides building communicative media skills irreplaceable for $21^{\text {st }}$ century active citizenship. However, with at-risk youth, the sociocultural aspects of media participation should be emphasised more than political aspects, as youth generally, especially at-risk youth, are difficult to get interested in formal, public politics in western democracies (e.g., Checkoway 2010; Dahlgren 2000; Percy-Smith and Thomas 2010). Percy-Smith and Thomas (2010) claim that compared to the rest of the world, in Western countries too much emphasis is placed on formal, public-sector decision-making in youth participation programmes. They point out that it is not enough for youth to be consulted and involved in decision-making; in order to become empowered, they must also see positive outcomes. For instance, in Finland, England and Australia, it appears that youth rarely influence decision-making in adult-governed areas (e.g., Black, Walsch, and Taylor 2011; Percy-Smith 2010, Percy-Smith \& Thomas 2010; 
Sotkasiira, Haikkola, and Horelli 2010). Thus, politically oriented media participation can backfire especially with at-risk youth, so leading into disempowerment.

In psychological studies, there has been outlined a theory of self-determination (SDT) specifying human needs that foster psychological growth and wellbeing (e.g., Deci and Ryan 2000; Ryan, Huta, and Deci 2008). SDT focuses on aspects of self-realisation, identifying competence, autonomy and relatedness as intrinsic needs that bring deep satisfaction for humans. The theory claims that learning is crucial for humans in adapting to new life situations and holds that there is satisfaction in learning for its own sake, creating a need for experiences of competence and selfefficacy. The need for autonomy and self-determination is based on the view that living beings tend towards coherence and self-regulation, and that personal needs are specified and processed in relation to environmental affordances. As opposed to experiencing coercive forces, control and pressure, one feels content in deciding and regulating one's own actions. However, autonomy does not mean total independence, but rather a sense of choice and volition in one's actions. SDT also argues that humans long to feel connected to and cared about by others. This need for relatedness is grounded in the human tendency to care for and protect its offspring. SDT argues that satisfaction of these three needs or motivations promote wellbeing. (E.g., Deci and Ryan 2000; Ryan, Huta, and Deci 2008).

While SDT examines wellbeing from the perspective of the individual, the theory can be criticised for bypassing influences such as cultural factors and the role of the welfare state on an individual’s wellbeing (e.g., King, Renó, and Novo 2014; White 2007). However, the redeeming feature of SDT is that it does not focus on material needs, such as housing, income or health. In a welfare state, such as Finland, where material needs are often already met, there is a natural emphasis on the significance of psychological needs such self-realisation.

SDT has been applied in media and game studies, as well as in educational sciences (e.g., Lee, Pate, and Cozart 2015; van der Spek 2012). The theory also offers a suitable framework for 
analysing the YPAM data because the study focuses on the individual dimension by identifying factors that support or limit youth’s participation. Furthermore, since the YPAM project handles creative media production, the data relate to issues of self-realisation more than to youth's material needs. In this text, the intention is not to criticise or further develop SDT but to assess whether media participation in youth work as a part of media education can contribute to the wellbeing of atrisk youth through increased competence, autonomy and relatedness. Following SDT, this article addresses the following three questions: Do at-risk youth have a need to experience competence, autonomy and relatedness? How can youth work employ media participation to engender these experiences? What kinds of challenges can arise during this process?

\section{Young People in the Limelight as an Action Research}

Youth marginalisation is a complex societal phenomenon that is far from resolved, thus it invites innovative, practice-based scientific research. The aim of the media education study Young People in the Limelight (YPAM), conducted in several locations around Finland from 2015-2017, is to expose the best pedagogical practices of promoting multiliteracies and public media participation and to develop new ways to empower the at-risk youth. This developmental aim calls for an experimental approach, such as action research, that affords constant testing, reflection and flexible changes during the fieldwork in order to find innovative ideas and teaching methods (e.g., Hearn et al. 2009; Reason \& Bradbury 2006). Action research also allows doing research with a community of practice, such as youth, rather than on them, thus appreciating their explicit and tacit knowledge and preventing further marginalisation of participants (e.g., Reason \& Bradbury 2006). In the YPAM, the at-risk youth were not only encouraged to engage with diverse media activities but also to reflect as co-researchers on what motivates and inspires youth to participate in, with and through media. By bridging theory and knowledge, action research is based on a rather different view of knowledge than traditional academic research as it does not privilege knowing through thinking 
over knowing through doing and generates knowledge through democratic dialogue with research participants (Reason \& Bradbury 2006). To sum up, the YPAM action study is pragmatic, transformative and substantially youth-based (see more Cresswell 1998).

Eight researchers of the YPAM implemented seven media workshops (sub-studies) for youth in collaboration with employees in each institution. The youth created art and media content (e.g., journalistic texts, photographs and a stage play) in these workshops and published their media content in authentic settings (e.g., on a blog, in a youth magazine, in an art exhibition or on stage). Each workshop (sub-study) can be seen as an independent piece of action research in which action cycles (i.e., planning, acting, observing and reflecting) varied from one to several, depending on the duration and context of that workshop. On the other hand, the pilot and seven workshops can be considered as a single case of deep action research—a spiral of multiple cycles—because they were in part conducted sequentially. The insights gained from the first workshop were passed on to researchers in the second workshop, who made adjustments to their workshop plans based on these insights and later communicated their critical insights to the researchers in the third workshop, and so on. So, in an action study, knowledge builds up in a systematic manner through an experimental and eclectic process of inquiry (e.g., Hearn et al. 2009; Reason \& Bradbury 2006).

The YPAM workshops were conducted mainly in the context of youth work in collaboration with municipal and non-governmental youth organisations. In Finland, as in other Nordic countries, municipal youth work plays an established role in terms of organising spare time activities for youth outside compulsory education and offering safe spaces for them to hang out together in places other than school. Almost all municipalities have a youth centre, house or space. Furthermore, there are non-governmental youth centres open for every child. For example, one YPAM sub-study was held at a café-style youth space where youth hang out in their spare time, while another workshop took place in a more closed youth house targeting at-risk youth. Another was conducted at a school-like 
workshop centre that is run by a city in southern Finland where unemployed youth are recruited to improve their communication and social skills.

The YPAM workshops drew on a pedagogy of multiliteracies, which aims to democratise learning conditions for the benefit of all children, allowing them to participate fully in public and community life. This pedagogy recognizes young people’s diverse backgrounds, lifeworlds, existing knowledge and learning skills. It embraces agency, collaborative work and multiple methods of learning, especially informal approaches. (E.g., Broderick 2014; Cazden et al. 1996.) While these ideas were endorsed in the YPAM, the four instructional phases of the pedagogy (i.e., situated practice, overt instruction, critical framing and transformed practice) were not rigorously applied because the objectives of Finnish youth work differ from those of schools. The non-formal goals of youth work are chiefly to support youth’s socialisation and growth as humans and citizens, including non-formal media education (e.g., Nieminen 2007). School pedagogies cannot be applied to it as such, as youth work is based on voluntariness and does not possess such demanding learning objectives as a school curriculum (e.g., Sercombe 2010). Consequently, youth work uses its own voluntary-based methods of participation (Sotkasiiri, Haikkola, and Horelli 2010).

Youth is regarded as a life phase of around 18 years during which individuals explore their identities and acquire culturally defined roles, which are shifting, as young people’s desires and practices, including media use, are in flux. (E.g., Sotkasiira, Haikkola, and Horelli 2010). Of around 100 young individuals, mainly 15-22 years old, that were enrolled in the YPAM workshops one third dropped out following the first meeting. Approximately half of the remaining participants were pupils or students, and the other half were either officially unemployed or outside the job market and school system. The participants were not considered marginalised, for instance, because some were still attending school and the unemployed youth had not been without work for long. In addition, they were not outside the reach of youth work and social services and they maintained some motivation to become active agents in their lives. Consequently, reinforcing their skills, 
identity and agency seemed a plausible way to advance their inclusion in society, especially through media participation because media is an integral part of the lives of most Finnish youth. However, the participants were considered to be at risk of marginalisation for various reasons, such as unemployment, learning difficulties, disabilities or social difficulties or having an immigrant background. Most of them had diminished motivation or ability to make personal life choices and maintain their autonomy. For ethical and policy reasons, the at-risk status of the participants was not mapped out on an individual basis. Instead, the participants were found by contacting institutions where at-risk youth are known to participate, live and hang out.

The YPAM data is largely qualitative and were collected using mixed methods (see more Cresswell 1998). The data comprises: (a) ten observation diaries written by eight researchers (1050 pages each), (b) individual interviews with 27 youth (10-40 min), (c) individual and group interviews with seven youth workers (40-80 min), (d) one discussion among two researchers, (e) four individual peer interviews involving young participants as interviewees and co-researchers (10-15 min), (f) one radio interview with three young people as interviewees and co-researchers, with the researcher as the host (approximately $30 \mathrm{~min}$ ), (g) written summaries of World Café discussions on twelve topics (groups) held among youth workers and researchers in two YPAM seminars, (h) media content produced by participants, (i) 44 background questionnaires (e.g., age, media usage) and (j) 27 questionnaires about the participants' experiences during the workshops.

In analysing the qualitative data, text paragraphs and photographs reflecting a similar theme were identified and gathered into a single text document using Atlas.ti software program. All data were categorised first in eight categories (codes) and then in fourteen categories. In the first set of eight categories, the data were classified as individual, organisational and technological dimensions of media participation, and further more as socio-cultural, societal-public and non-media-related participation. The second set of fourteen categories was formed through a literature review, a preliminary reading of the data and YPAM keywords (i.e., motivation, social interaction, autonomy, 
and, self-expression and art). During a close reading of the coded text documents, three needs related to wellbeing - competence, autonomy and relatedness - were identified by reflecting the data against the literature (e.g., Deci and Ryan 2000; Ryan, Huta, and Deci 2008). The following section discusses these needs in relation to the findings.

\section{Competence: Showing Trust in Young People from the Outset}

The need for competence appeared implicitly in the participants' speech and behaviours during the YPAM workshops. While it was hypothesised that the youth would be interested in self-expression in and through the media, many were motivated by the opportunities to improve their technical skills, such as photography and film editing. There is in fact evidence that in order to participate in media projects, at-risk youth are not motivated by issues such as independence, financial reward or societal influence, but rather by the motivation to improve their skills and technical competence (e.g. Bloustien 2007, 452; Vickery 2014, 85).

The participants' need for competence also manifested through the elevated positions provided for them during the workshops. Particularly those participating in a media-based theatre workshop emphasised that they were not motivated by the opportunity to perform but by the opportunity to act as informants and co-researchers. They stressed that the play presented a chance to communicate divergent information about their lived experiences during challenging transitions between schools or when moving into working life. Therefore, they appreciated the chance to act as experiential experts, as most YPAM participants did. In all workshops yet another indicator was that peer tutoring increased engagement with tasks and interaction among the youth who were typically withdrawn and, as a result, they seemed to gain a sense of self-efficacy (see also Carr and Jitendra 2000, 42; Charmaraman 2013, 107; Ryan, Huta, and Deci 2008, 154). The body language revealed that they were often flattered when referred to as 'artists' in feedback situations during workshops and exhibition openings, and when they were asked to act as experiential experts in 
public settings such as in a radio show or seminar. To sum up, the participants appreciated situations in which their existing expertise was acknowledged.

Although the at-risk youth longed for a sense of competence, their pursuit of this experience was conflicted. The behaviour of most participants revealed that they had low self-esteem, and so they expected to perform poorly in media tasks. Some did not try hard enough and underachieved, while other were so self-critical they accomplished very little. Youth workers especially emphasised the importance of positive feedback when empowering at-risk youth. Many young people initially said they did not wish to receive feedback. However, after hearing some nice comments, many started to ask for more feedback with an apparent increase in their motivation to engage with tasks and attend workshops (see also Broderick 2014, 206; Carr and Jitendra 2000, 40). Consequently, it became important to challenge the youth and provide them with realistic opportunities for selfrealisation, enabling them to excel beyond their perceived limits (see also Broderick 2014; Bloustien 2007). The question, then, is how best to encourage timid, withdrawn and uninterested youth to take risks, get involved and commit to tasks.

As noted above, positioning youth as experts (i.e., co-researchers, experiential experts, peer tutors) was important, as it built a sense of trustworthiness, value and competence from the outset, helping to get them out of the victim stance (see also Bloustien 2007; Carr and Jitendra 2000, 40). Another factor was the development of self-knowledge and self-reflection skills (see also Carr and Jitendra 2000, 42). Tasks facilitating the exploration of topics of their possible interests, possible talents and suitable working methods, allowed the participants to discover their strengths and interests (see also Black, Walsch, and Taylor 2011, 47; Rodríguez-Jiménes and Gifford 2010, 35; Vickery 2014, 87). Opportunities for exploration were provided for example through quick, varied media tasks that allowed the participants to receive feedback frequently, thus developing their selfreflection skills. Once they became conscious of their strengths, participants were better able to draw on these, in turn, reinforcing their sense of competence (see also Carr and Jitendra 2000, 43). 
Authentic opportunities to perform on stage and in the public sphere through media, such as publishing texts in a youth magazine and participating in exhibitions, were particularly important for the youth to experience competence. The youth seemed to interpret the act of publishing as a sign of adults' trust in them and an acknowledgement of their competence. However, publishing alone was not enough — in order to feel competent, it was crucial that they felt excelling themselves in their creative work. These opportunities of publishing motivated them to get involved, commit to tasks and attend workshops (see also Carr and Jitendra 2000; Charmarman 2013, 112; Hopkins 2010; Vickery 2014, 82). However, their enthusiasm usually began to grow only after their first public performance (see also Broderick 2014, 202).

\section{Autonomy: Creating Friendly Situations in which to Express Self-Determination}

There is a growing trend among technologically literate youth to produce films on their own, meaning outside the film industry and without the support of institutional finance and marketing channels (Huttunen 2014). While YPAM youth exhibited a similar need for autonomy and selfdetermination, their capacity for autonomy differed. Most had published some of their creative products online (e.g., photos, videos and texts). However, in interviews, many regretted, for example, not making videos lately, or they wished to accomplish more. So, the participants had a need to do something on their own terms. Moreover, during the workshops, the participants appreciated opportunities to choose between options, however minor, to influence the content of a media task or to decide on a schedule, for example. However, it was difficult for many participants to express their will, maintain self-determination and regulate their own activities.

Encouraging the youth to express their opinions verbally during the workshops not only reinforced their autonomy, but also increased their enthusiasm and commitment to media tasks and workshop attendance. Yet, it was challenging to inspire them to participate on their own terms since many were afraid to talk and some tried to please the adults, for instance. While many practices 
commonly used in youth work (e.g., games) functioned well, some social media applications (e.g., Kahoot) offered additional ways to encourage verbal expression, as many felt more comfortable expressing their opinions anonymously and in written form rather than orally (see also Maier and Fisher 2007, 175). Dekelver, Van den Bosch and Engelen $(2011,62)$ also suggest that these applications 'helped the young people become more confident as it allowed some shy individuals to interact more easily’. Although social media applications can promote self-expression and democracy, their use is not unproblematic. In the YPAM, some youth institutions looked kindly on social media use, but those with a strong focus on at-risk youth were less enthusiastic or even opposed it for protectionist reasons, for instance, since some applications reveal the user's phone number to others, creating opportunities for cyberbullying.

Offering the youth friendly situations that presented a low threshold for expression of opinions, freedom of choice and self-determination proved to be the key to supporting at-risk participants’ autonomy and social involvement. In addition to social media applications, these opportunities arose especially through informal activities (e.g., photography excursions) and working methods (e.g., peer tutoring, project-based learning and creative work) (see also Carr and Jitendra 2000; Dekelver, Van den Bosch, and Engelen 2011). By downplaying power hierarchies among adults and youth, informality can relieve inhibitions related to fear of authority figures.

Youth institutions strongly targeted at at-risk youth, however, considered informality to be problematic. The staff insisted that unstructured ('chaotic-like') situations can create insecurity in youth, and that joint decision-making can lead to conflict. These reservations were justified with respect to some individuals with severe insecurity issues. However, it is worth questioning at what point one becomes unduly paternalistic. Surely, daily life skills include learning to cope with insecurities and conflicts. On the other hand, how much pushing is reasonable? Like Maier and Fisher (2006-2007, 189), it was discovered in the YPAM study that a lack of structure, such as too much freedom to choose, can become paralysing rather than liberating for at-risk youth (see also 
Rodríguez-Jiménez and Gifford 2010, 39). For example, a task to write a story from any topic was confusing for many participants. Consequently, autonomy was best supported by media tasks with clear structure and guidance. However, in accomplishing these structured tasks, informal activities and working methods enhanced the participants’ engagement and autonomy.

For many participants, taking the initiative to start or complete a major project, such as an exhibition or a blog, independently seemed overwhelming. Although too much choice and freedom was paralysing, they appreciated the opportunity to participate in decision-making, even if they were unable to take advantage of it. Consequently, full participatory roles and autonomy proved unfeasible and may not even be a desirable goal for the at-risk participants (Head 2001, 546). Nevertheless, the mere opportunity to express their opinions is insufficient for youth empowerment, Percy-Smith $(2010,108$.$) stresses. In the YPAM as well, it was discovered that the youth must see$ the positive consequences of their participation, in order to feel influential and become more autonomous. Therefore, it is crucial to provide friendly situations where at-risk youth can actually demonstrate autonomy. The youth workers did acknowledge the importance of consultation but many times found it difficult to fulfil the youth's wishes, for example due to policy or security reasons. Thus, the at-risk youth lacked the opportunity to truly influence their surroundings.

\section{Relatedness: Providing Individual Support and Informal Group Interactions}

In the interviews, many YPAM participants explicitly said that one of the reasons they enrolled in the voluntary workshops was to experience a sense of community, while others merely praised the workshop’s group dynamic or complained about the lack of it. However, many participants had some degree of difficulty with social interactions for various reasons (e.g., shyness, depression, being bullied and limited language skills). Additionally, some individuals (e.g., those with Asperger's Syndrome) preferred individual rather than group work, as they did not have a strong need for a sense of community. Yet, they still appeared to long for the feeling of being connected to 
and cared about by others. So, significant variations were observed in the participants' ability to interact socially and their need for relatedness.

Supporting relatedness in the workshops was twofold. First, it required reinforcing the participants' self-esteem and self-confidence as individuals, which increased their courage to relate to others. Providing this support involved appreciating their opinions and competence. Building trustworthy relationships with others also helped participants to gain acceptance of their identities and to feel safe when participating in group activities with and through media. Although face-toface interactions were central for building reliable relationships, the interactions through social media also strengthened the relatedness and sense of belonging between the participants. Moreover, receiving positive feedback on their self-expression based media content—and thus implicitly on their identities—grew their self-esteem. Their enthusiasm for the tasks that facilitated identity processing confirmed their desire of comments on their identities (see also e.g., Broderick 2014, 206; Maier and Fisher 2006-2007). However, simultaneously, they were very sensitive to discuss their identities. Autobiographical and identity-related activities were indeed delicate matters because talking about personal experiences can be disempowering and open up an inner process requiring therapeutic help.

Secondly, relatedness was facilitated by creating situations where participants could readily feel a sense of community. Many practices commonly used in youth work (e.g., group games) facilitated social interactions. The participants were engaged in contact with others especially in informal situations face-to-face and through media. Small groups, peer tutoring, playful and creative atmospheres and social media (e.g., WhatsApp, Instagram) proved helpful for engendering such informal situations and furthermore relatedness (see also Broderick 2014). Especially social media, which is an integral part of youth's lifeworld, appeared to have the potential to promote informality and relatedness. However, this was not straightforward because many at-risk youth seemed to feel strong peer pressure. In fact, they were no more eager to start a conversation through 
social media than face-to-face. During the workshops, the participants were encouraged to join the interactions on social media through compulsory but informal tasks. After they had discussed for a while, the talk would sometimes continue; this in turn enhanced the sense of community and reinforced their subsequent face-to-face interactions. In the absence of face-to-face contact, some felt a sense of belonging through the online interactions (see also Dekelver, Van der Bosch, and Engelen 2011, 63).

More effort should have been invested in initiating icebreaking discussions online; however, this point of innovation was not reached in many workshops due to the policies of youth institutions and the accompanying resistance of employees in relation to social media use, as mentioned above. Similar challenges were identified by Vickery (2014, 89-91) whose school-based digital media project revealed how policies are formulated 'to minimize the risks associated with teens interacting in social networks, such as strangers, predators, exposure to harmful content and distractibility’. In so doing, she notes that these policies block opportunities for social interaction, developing network literacies and improving youth’s coping mechanisms for handling feedback. The present study also confirms the findings by Dekelver, Van den Bosch and Engelen $(2011,65)$ who report that employees of youth institutions had little or no experience with using social media software with atrisk youth and were not informed about the potential of such software.

Face-to-face media productions (i.e., participation with media) also exhibited the potential to reinforce relatedness among at-risk youth. Different media seem to offer intrinsically different opportunities for relatedness, although diverse social interaction is possible within every medium. For example, photography was especially suited to individuals who had significant difficulty with social interactions (e.g., those with Asperger's Syndrome or limited language skills). It is natural to photograph independently and yet feel a sense of belonging, for instance, during a photography excursion with peers or a group project (e.g., exhibition) where each person produces an independent piece of work for the whole. So, photography supports both independent work and 
relatedness to the extent that the at-risk youth can accommodate it. A joint photography project such as an exhibition can also create responsibility and group ownership even when little cooperation is required. In contrast, filmmaking often requires much interaction and cooperation. Each person has their own job to do, but collaborations are also required to create a unified film. However, Broderick (2014) notes that such major shared responsibility creates a strong sense of project ownership and community, and taking responsibility can positively affect motivation and autonomy (see also Maier and Fisher 2007; Percy-Smith 2010).

\section{Conclusion}

Using SDT to analyse the YPAM data revealed that at-risk youth have the needs for competence, autonomy and relatedness, but have difficulties gaining these experiences. Incorporating such media education into youth work that affords participation in, with and through media proved valuable with at-risk youth because it offered them diverse opportunities to fulfil these needs, besides building their media literacy and communicative media skills.

A vital way to support the attainment of a sense of competence was noted to be the trust in the participants' skills and expertise from the outset-for instance, by offering at-risk youth expert positions and authentic opportunities to show their competence publicly. Other important activities for engendering competence included supporting their self-esteem and self-reflection skills and assisting them to excel in their creative work. Their growing sense of competence increased their motivation to participate in media tasks and in decision-making, as well as to attend workshops and relate to others. Therefore, fulfilling the need for competence was especially important because it contributed to strengthening autonomy and relatedness as well.

An effective way to support autonomy and relatedness was to create informality through friendly situations wherein to easily express volition, self-determination and connect to others. However, informality should occur within structured, well-guided activities in order to ensure that 
youth can grasp the agenda and are not made to feel insecure. Furthermore, relatedness was enhanced by reinforcing self-esteem, which was achieved by appreciating the individual's opinions, identity and competence and by building trustworthy relationships. To sum up, the YPAM study confirms that integrating media participation in media education in the context of youth work, surely also in schools, can help to fulfil at-risk participants’ needs for competence, autonomy and relatedness. The question of whether fulfilling these needs truly contributes to their general wellbeing is however beyond the scope of this article. Furthermore, as Hopkins $(2010,190)$ points out, even if youth participation programmes increase wellbeing and empower individuals, they do not change the structural and societal problems that contribute to youth's indisposition and disempowerment.

Overall, the practices of youth institutions participating in YPAM proved to act most problematic with respect to youth's autonomy, due to staff's reservations about social media, informality and democratic decision-making. For example, social media offered fresh opportunities to build youth's autonomy and relatedness, but this was limited due the protective tendencies. Clearly, supporting the autonomous participation of at-risk youth requires finding a balance between protection and participation (Percy-Smith and Thomas 2010; Pienimäki and Kotilainen 2017). Yet, highly paternalistic actions do not support the autonomy and inclusion of at-risk youth. Therefore, it is necessary to develop, for instance, innovative and safe ways to use social media as well as custom developed social software for at-risk youth (Dekelver, Van den Bosch, and Engelen 2011).

The use of the action research approach appeared as valuable, since it involved the young participants as co-researchers, which helped to reveal their need for competence and the value of trusting in them from the outset. Furthermore, since this approach allows a researcher to change the course of action flexibly and test hypotheses as they arise during the fieldwork, it was able to reveal in the workshops, for example, the ability of at-risk youth to gain autonomy and self-determination. 
So, these 'tests' within one sub-study and across different sub-studies allowed the researchers to explore the functionality and significance of diverse methods of youth media participation.

The SDT was well suited to analyse media participation in the YPAM study. It illustrated especially the social-cultural aspects of media participation from a new perspective by revealing that social and communicative media skills can create satisfaction for its own sake by engendering experiences of competence, autonomy and relatedness, and so are not only valuable for democratic citizenship (e.g., Dahlgren 2000). This aligns with the findings in the game-design studies by Spek (2012) who found that the players' increased feelings of competence contributed to prolonged participation in a computer game. Other studies show, in turn, that the experiences of relatedness and autonomy can lead to more frequent liking, commenting and sharing on social media (e.g. Lee, Pate, and Cozart 2015). The YPAM study suggest that the satisfaction of the three needs can arise through varied media engagement, thus making media participation as a part of media education a promising method of improving the wellbeing of at-risk youth besides building their agency, multiliteracies and communicative media skills.

The Kone Foundation (Finland) supported this work. The author reports not potential conflict of interest.

\section{References}

Black, R., L. Walsch, and F. Taylor. 2011. "Young People on the Margins: What Works in Youth Participation.” Youth Studies Australia, 30 (1): 42-48.

Bloustien, G. 2007. ““Wigging People Out’: Youth Music Practice and Mediated Communities.” Community \& Applied Social Psychology, 17 (6): 446-462.

Broderick, D. 2014. “Collaborative Design: Participatory Culture Meets Multiliteracies in a High School Arts Community.” Adolescent \& Adult Literacy, 58 (3): 198-208.

Carpentier, N. 2011. Media and Participation: A Site of Ideological-Democratic Struggle. Bristol: Intellect. 
Carr, T., and A. K. Jitendra. 2000. "Using Hypermedia and Multimedia to Promote Project-Based Learning of At-Risk High School Students.” Technology Trends, 36 (1): 40-44.

Cazden, C., B. Cope, N. Fairclough, J. Gee, et al. 1996. “A Pedagogy of Multiliteracies: Designing Social Futures.” Harward Educational Review, 66 (1): 60-92.

Charmaraman, L. 2017. “Congregating to Create for Social Change: Urban Youth Media Production and Sense of Community.” Learning, Media and Technology, 38 (1): 102-115.

Checkoway, B. 2011. "What is Youth Participation?” Children and Youth Services Review, 33: 340-345.

Cresswell, J. W. 1998. Qualitative Inquiry and Research Design: Choosing Among Five Traditions. Thousand Oaks: SAGE.

Dahlgren, P. 2000. “The Internet and the Democratization of Civic Culture”. Political Communication, 17 (4): 335-340.

Deci, E. L., and R. M. Ryan. 2000. “The 'What' and 'Why’ of Goal Pursuits: Human Needs and the Self-Determination of Behavior.” Psychological Inquiry, 11 (4): 227-268.

Dekelver, J., W. Van den Bosch, and J. Engelen. 2011. "Supporting Social Inclusion of Youth at Risk Using Social Software: Impact, Sustainability and Evaluation, One Year after Pilot Testing.” Housing, Care and Support, 14 (2): 61-66.

Hart, R. A. 1992. Children's Participation: From Tokenism to Citizenship. Florence: UNICEF Innocent Centre.

Head, B. W. 2011. "Why Not Ask Them? Mapping and Promoting Youth Participation.” Children and Youth Services, 33: 541-547.

Hearn, G., J. Tacchi, M. Foth, and J. Lennie. 2009. Action Research and New Media. Concepts, Methods and Cases. Cresskill: Hampton Press.

Hopkins, L. 2010. “YouthWorx: Increasing Youth Participation through Media Production’. Sociology, 47 (2): 181-197.

Huttunen, J. 2014. Redefining Aspects of Participation for Amateur Film-Makers in the Nordic Countries.” Interactions: Studies in Communication \& Culture, 5 (3): 365-379.

Jenkins, H., R. Purushotma, M. Weigel, K. Clinton, and A. J. Robison. 2009. Confronting the Challenges of Participatory Culture. Media Education for the $21^{\text {st }}$ Century. Cambridge: MIT Press, MacArthur Foundation.

King, M. F., V. F. Renó, and E. M. L. Novo. 2014. “The Concept, Dimensions and Methods of Assesment of Human Well-Being within a Socioecological Context: A Literature Review.” Social Indicators Research, 116: 681-698. 
Kotilainen, S. \& Pathak-Shelat, M. 2015. ”Media and Information Literacies and the Well-being of Young People. Comparative Perspectives”. In Reflections on Media Education Futures, edited by S. Kotilainen \& R. Kupiainen, 146-157. Göterborg: The International Clearinghouse on Children, Youth \& Media and Nordicom.

Lee, E., J. A. Pate, and D. Cozart. 2015. “Autonomy Support for Online Students.” TechTrends, 59 (4): 54-61.

Maier, R. B., and M. Fisher. 2006-2007. “Strategies for Digital Storytelling via Tabletop Video: Building Decision Making Skills in Middle School Students in Marginalized Communities.” Educational Technology Systems, 35 (2): 175-192.

Me-säätiö [Me Foundation]. 2017. http://www.mesaatio.fi/suomessa-on-syrjassa-tanaan-69-000nuorta/

Myrskylä, P. 2012. Hukassa—Keitä ovat syrjäytyneet nuoret? Helsinki: EVA. http://www.eva.fi/wp-content/uploads/2012/02/Syrjaytyminen.pdf

Nieminen, J. 2007. ”Vastavoiman hahmo - Nuorisotyön yleiset tehtävät, oppimisympäristö ja eetos”. In Nuorisotyötä on tehtävä - Menetelmien perustat, rajat ja mahdollisuudet, edited by T. Hoikkala \& A. Sell, 21-43. Helsinki: Nuorisotutkimusverkosto \& Nuorisotutkimusseura.

Percy-Smith, B. 2010. “Councils, Consultations and Community: Rethinking the Spaces for Children and Young People’s Participation.” Children's Geographies, 8 (2): 107-122.

Percy-Smith, B., and N. Thomas. 2010. “Conclusion: Emerging Themes and New Directions.” In $A$ Handbook of Children and Young People's Participation: Perspectives from Theory and Practice, edited by B. Percy-Smith and N. Thomas, 356-366. London: Routledge.

Pienimäki, M. and S. Kotilainen. 2017. "Youth Participation in Research on Multiliteracies: Ethical Perspectives.” Media Education Research, 8 (1): 115-132.

Reason, P., and H. Bradbury. 2006. "Inquiry and Participation in Search of a World Worthy of Human Aspiration.” In A Handbook of Action Research, The Concise Paperback Edition, edited by P. Reason and H. Bradbury, 1-14. London: SAGE.

Rodríguez-Jiménes, A., and S. Gifford. 2010. “Finding Voice: Learnings and Insights from a Participatory Project with Recently Arrived Afghan Young Men with Refugee Backgrounds.” Youth Studies Australia, 29 (2): 33-41.

Ryan, R. M., V. Huta, and E. L. Deci. 2008. “Living Well: A Self-Determination Theory Perspective on Eudaimonia.” Journal of Happiness Studies, 9 (1): 139-170.

Sercombe, H. 2010. Youth Work Ethics. London: Sage. 
Sotkasiira, T., L. Haikkola, and L. Horelli. 2010. "Building towards Effective Participation: A Learning-Based Network Approach to Youth Participation.” In A Handbook of Children and Young People's Participation: Perspectives from Theory and Practice, edited by B. PercySmith and N. Thomas, 174-183. London: Routledge.

Thumim, N. 2010. "Self-representation in museums: therapy or democracy”. Critical Discourse Studies, 7 (4): 291-304.

United Nations. 1989. Convention on the Rights of the Child.

http://www.ohchr.org/Documents/ProfessionalInterest/crc.pdf

van der Spek, E. D. 2012. “Towards Designing for Competence and Engagement in Serious

Games.” In Serious Games Development and Applications, SGDA 2012 Lecture Notes in Computer Science, vol. 7528, edited by M. Ma, M. F. Oliveira, J. B. Hauge, H. Duin, and K. D.Thoben. Berlin and Heidelberg: Springer.

Vickery, J. R. 2014. “The Role of After-School Digital Media Clubs in Closing Participation Gaps and Expanding Social Networks.” Equity \& Excellence in Education, 47 (1): 78-95.

White, J. 2007. “Wellbeing and Education: Issues of Culture and Authority.” Journal of Philosophy of Education, 41 (1): 17-28. 